\title{
Rescuing the duty to rescue
}

\author{
Tina Rulli, ${ }^{1}$ Joseph Millum ${ }^{1,2}$
}

${ }^{1}$ Clinical Center Department of Bioethics, National Institutes of Health, Bethesda, Maryland, USA

${ }^{2}$ Fogarty International Center, National Institutes of Health, Bethesda, Maryland, USA

\section{Correspondence to} Dr Tina Rulli, Clinical Center Department of Bioethics, National Institutes of Health, 10 Center Drive Bldg 10, Room 1C118, Bethesda, MD 20892, USA tinarull@gmail.com

Received 11 June 2013 Revised 29 October 2013 Accepted 2 April 2014 Published Online First 30 April 2014

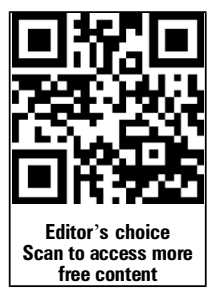

\section{SLinked}

- http://dx.doi.org/10.1136/ medethics-2014-102109

\section{CrossMark}

To cite: Rulli T, Millum J. J Med Ethics 2016;42: 260-264.

\section{ABSTRACT}

Clinicians and health researchers frequently encounter opportunities to rescue people. Rescue cases can generate a moral duty to aid those in peril. As such, bioethicists have leveraged a duty to rescue for a variety of purposes. Yet, despite its broad application, the duty to rescue is underanalysed. In this paper, we assess the state of theorising about the duty to rescue. There are large gaps in bioethicists' understanding of the force, scope and justification of the two most cited duties to rescue - the individual duty of easy rescue and the institutional rule of rescue. We argue that the duty of easy rescue faces unresolved challenges regarding its force and scope, and the rule of rescue is indefensible. If the duty to rescue is to help solve ethical problems, these theoretical gaps must be addressed. We identify two further conceptions of the duty to rescue that have received less attention - an institutional duty of easy rescue and the professional duty to rescue. Both provide guidance in addressing force and scope concerns and, thereby, traction in answering the outstanding problems with the duty to rescue. We conclude by proposing research priorities for developing accounts of duties to rescue in bioethics.

\section{INTRODUCTION}

Clinicians and health researchers frequently encounter opportunities to rescue people-to avert threats of near-certain, serious harm. Rescue cases can generate a moral duty to aid those in peril. As such, bioethicists have leveraged a duty to rescue for a variety of purposes, including: to criticise the use of placebo controls in trials in developing countries $^{1}$; to defend duties of researchers to return urgent incidental findings ${ }^{2}$ and provide ancillary care $^{3}$; to argue for a duty to participate in research ${ }^{4}$ and to become an organ donor ${ }^{5}$; to defend allocating resources to develop drugs for rare diseases ${ }^{6}$ and to fund costly end-of-life care and other highcost, low-benefit procedures. ${ }^{7-9}$ Beyond this, the vast amount of health-related urgent need in the world means that novel applications of a duty to rescue are all but inevitable.

In this paper, we examine the theoretical basis of rescue duties as they are used in bioethics. Bioethicists frequently treat the duty to rescue as though the criteria for its application are settled. However, there are large gaps in our understanding of the force, scope and justification of the two most cited conceptions of a duty to rescue in bioethicsthe individual duty of easy rescue and the institutional rule of rescue. We argue that the rule of rescue is indefensible as an ethical principle. There is a duty of easy rescue, but its application in nonideal cases requires substantial theoretical work if it is to help solve ethical problems. We introduce two conceptions of rescue duties: an institutional duty of easy rescue and a professional duty to rescue. Both offer more guidance in addressing force and scope concerns and can thereby provide traction in answering outstanding problems with the duty of easy rescue. We conclude by proposing research priorities to fill the remaining gaps we have identified in accounts of duties to rescue.

\section{THE DUTY OF EASY RESCUE}

The standard conception of the duty of easy rescue states that if someone can prevent a serious harm to another person at minimal cost to herself, then she has a moral duty to do so. If someone passes by a shallow pond and sees a child drowning, she has a duty to wade in and save him, even at the cost of soiling her clothes or being late to work. ${ }^{10}$ This is a general duty; that is, a duty that all people have in virtue of being moral agents.

The individual duty of easy rescue faces two major challenges. The first concerns its force: how easily is this duty outweighed by potential costs to the agent? The pond example intuitively suggests that at least there is a duty to rescue when the cost to the rescuer is minimal. Yet many bioethicists, following Tom Beauchamp and James Childress's lead, draw the upper bound of the duty at the same level: individuals have a duty to rescue only if their actions 'would not present very significant risks, costs, or burdens' to them. ${ }^{11}$ Though it is commonly accepted, this restriction is questionable.

Suppose someone could safely rescue a child caught on the railroad tracks by pushing his expensive sports car in the way of an on-coming train. Many people think he would have a moral duty to bear this great personal cost in order to save the child's life. ${ }^{12}{ }^{13}$ Moreover, medical ethics already recognises a more than minimal duty to rescue in the form of the duty to warn. Psychiatrists have a legal and moral duty to warn third parties about the threats of a dangerous patient, ${ }^{14}$ and clinicians have duties to inform family or third parties of their patients' infectious disease status or genetic risks when an actionable intervention against the threat exists. ${ }^{15}$ The duty to warn can conflict with and override a doctor's duty of confidentiality to her patient. In the USA, doctors who breach confidentiality risk violating HIPAA or various state regulations, which could lead to civil or criminal liability ${ }^{16}$ The burden of the duty to warn can, therefore, be more than minimal.

Without agreement on the force of the duty to rescue, bioethicists will not agree on when it applies. Consider the following case: 
Investigators in Mali studying malaria discover a research subject with a severe congenital cardiac defect unrelated to the study. Her defect is untreatable in Mali, though she could be flown to the researchers' home country to receive treatment. Without treatment, she faces a high risk of death. ${ }^{17}$

Do the investigators have a duty to rescue in this case, that is, to fly the subject to another country for life-saving, but expensive heart surgery? Such a rescue would be very costly as a personal monetary burden to the researchers or as a monetary or research cost to the sponsors. A mere duty of easy rescue would not require investigators to take these measures. Indeed, the duty of rescue is oftentimes dismissed as a possible ground for ancillary care obligations under the assumption that it is minimally demanding — other duties must explain researchers' ancillary care obligations. ${ }^{18}$ But if the duty to rescue can require more costly sacrifices, as the examples of the sports car and the duty to warn suggest, then the medical evacuation might be required. Since the force of the duty to rescue has not been established, we cannot determine whether and how it applies to this case. Likewise, we cannot confidently ascertain how frequently a duty to rescue would entail a duty to return incidental findings or provide costly end-of-life care.

The second major challenge concerns the duty's scope: how broad is the range of cases to which the duty applies? Even if the duty is limited to low-cost cases, there may be an overwhelming number of low-cost opportunities to rescue. Given the amount of great need in the world that can be met at minimal burden, such proliferation is a real threat. For example, researchers working in sub-Saharan Africa may have a duty of easy rescue to provide antimalarial drugs to participants who present with symptoms of cerebral malaria, even when they are studying an unrelated condition. Doing so is low cost and meets a critical need. But, likewise, they could treat many non-subjects in the surrounding population at low cost. Indeed, researchers who do not encounter this need at all could send a comparable amount of money to treat needy children elsewhere in the world. Insofar as the duty to rescue is a general duty, everyone with extra means has this duty. The challenge is to either accept the counterintuitive and demanding proliferation of rescue obligations or to find a principled way to limit the duty's scope. $^{19} 20$

\section{THE RULE OF RESCUE}

An intuitive way to limit the proliferation of duty to rescue cases is to confine it to cases in which the rescuer encounters a unique emergency with an identifiable victim. This would limit the duty to cases like the drowning child, while excluding cases of distant need.

This brings us to the second concept of a duty to rescue often discussed in bioethics: the rule of rescue. The rule of rescue describes a psychological tendency to judge that we ought to rescue identifiable victims, even at great cost. ${ }^{7 i}$ The rule of rescue is typically invoked by doctors and bioethicists assessing the distribution of limited resources over a population. As such, it is usually applied to institutional contexts.

The rule of rescue was foundational in the debates leading up to Oregon's Health Plan reform in 1989. In 1987, Coby Howard, a 7-year-old with leukaemia, died after being denied a

${ }^{\mathrm{i}}$ The rule of rescue has two main components: it prioritises saving one or few lives at the opportunity cost of providing a large number of other people with smaller benefits, and it prioritises identifiable over unidentified lives. Here, we focus on the latter component. bone marrow transplant under Medicaid (the US health insurance programme for people with low incomes). Coby's case was widely televised and generated widespread moral outrage at the Oregon healthcare system, prompting reform. Though the legislature would ultimately decide to prioritise expanding healthcare to many people rather than funding high-cost procedures for a few, the public outrage on Coby Howard's behalf, and the public's general discontent with 'rationing,' illustrate the powerful tendency to prioritise saving identifiable lives even at great opportunity cost to many others. ${ }^{21}$

The rule of rescue describes a psychological tendency; but it is often implicitly endorsed as a moral principle. Justifying such a principle poses significant challenges. In particular, what does it mean for a person to be identifiable ?i $^{\text {ii }}$ Must one know the identity of a person in question in order to have a duty to rescue her? This seems implausible-surely one must rescue the drowning child even if she is a stranger. Perhaps, then, it is just a matter of being able to single out the person in need or a matter of her physical proximity. But identifiability and physical proximity do not restrict the scope of the duty to rescue in a way that would satisfy those who desire such a restriction in the first place. Most visitors and residents of Calcutta, for example, are soon inured to the numerous beggars and malnourished street children, despite their identifiability and proximity. Donating to help them is typically regarded as merely charitable, not morally required.

Attempts at providing a morally significant definition of identifiability have met formidable criticism from philosophers. ${ }^{10} 12$ In the end, bioethicists seem to use identifiability to indicate that the victim is seen as an individual rather than a mere statistic or one person among many similarly situated people. ${ }^{6}$ Identifiability defined this way, however, simply collapses into salience of the victim's need. This explains why people with especially compelling backstories or gruesome symptoms are often the beneficiaries of resource-intensive rescue, while less salient cases go unaddressed. But prioritising salience of need is an artefact of our psychology; salience of need does not constitute any moral reason for favouring some people over others. ${ }^{22}$

Limiting the duty to rescue to encounters with identifiable agents is indefensible. As such, the rule of rescue does not solve the original scope worries about the duty to rescue.

Without guidance on the force and scope of the duty to rescue we cannot confidently apply it to the difficult cases in medical ethics in which we want to know whether doctors, researchers, or government bodies have an obligation to meet an urgent need. The duty to rescue needs rescuing.

\section{REFOCUSING THE DUTY TO RESCUE FOR BIOETHICISTS}

Force and scope problems plague theorising about the duty to rescue generally. However, some progress can be made by focusing on the different actors who come to have duties to rescue. We propose that bioethicists should focus on the duties to rescue possessed by institutions and professionals, in addition to individual moral agents. Below, we discuss the potential that focusing on institutional and professional duties has for addressing the force and scope concerns identified above. We conclude

ii The identifiability captured by the rule of rescue phenomenon should not be contrasted solely with statistical lives - those lives that might be impacted in the future by some action. Rather, identifiable contrasts with unidentifiable, which includes statistical lives, people whose identities are unknown to an agent, and people who are one among many other similarly placed others, whose identities are not salient. 
by proposing a research programme for the development of conceptions of duties to rescue in bioethics.

\section{Focus on institutions}

First, bioethicists should consider the duty to rescue as it applies to institutions, not just individuals. By institutions we mean collectively shared social schemes responsible for the distribution of benefits and burdens across members in the collective, and primarily, we have in mind government institutions. Oftentimes, bioethicists speak of the duty to rescue that a clinician or researcher has in virtue of being a moral agent. But, more accurately, this agent would use institutional resources to enact a rescue at an opportunity cost to healthcare elsewhere. Focusing on institutions over individuals brings this wider context into focus.

The institutional duty to rescue differs from the individual duty to rescue in two important ways. First, it is held by an institution or institutional actor to populations rather than to individuals. Second, institutional obligations are not general, they are held to a specific population. As such, the institutional focus can provide guidance on the scope of a duty to rescue. Where with the individual duty to rescue it was unclear why an agent would have a duty to rescue some specific person rather than another in similar need, an institutional focus prioritises individuals for which an institution is responsible. Despite the great amount of need in the world, institutions have primary responsibility to address the needs of their own constituents.

The institutional nature of the duty can also assuage concerns about its force. Giving absolute priority to people in need of rescue over people with lesser needs would be unfair. Institutions have obligations to all of their members, and so there is some threshold at which an institution should forgo providing a costly rescue to some individual so that it can provide lesser benefits to a larger number of people. A plausible institutional duty of rescue, then, will be limited to cost-effective 'easy' rescues. Though we cannot specify the threshold for easy rescues here, a limited institutional duty of easy rescue can be motivated in a way that a limited individual duty of rescue cannot. In the latter case, the motivation for limiting the demands is the agent's personal interests. As noted above, it is controversial whether and when personal interests should defeat a duty to rescue. In the institutional case, the motivation is fairness to other institutional members who also have a claim on institutional resources. Costs to members to whom the institution has obligations to benefit provide solid grounding for limiting the institution's duty to rescue to easy cases.

Thus, the institutional duty of easy rescue differs from the rule of rescue by implying a cost threshold and a feasibility requirement for rescues that receive priority: it applies to those rescues that can be met at relatively low cost. Further, it does not unjustly select beneficiaries in virtue of their salience; it prioritises them based on need. Need is a morally relevant consideration reflected in a popular strand of thinking about justice, which requires that institutions give some priority to those people who are worst off (prioritarianism). ${ }^{\text {iii }}$

There is yet another way in which an institutional focus can address concerns about the force of rescue duties, that is, how demanding they are. Substantial institutions can respond to very

\footnotetext{
iii Prioritarianism is a more expansive theory that prioritises the worse-off, generally; it is not limited to cases in which people need rescuing. However, the institutional duty of easy rescue could be grounded in the same considerations that ground prioritarianism.
}

demanding rescues without any one person incurring a large unredressed burden because the burdens can be spread across individuals. For instance, taxpayers fund the fire department to conduct rescue operations, sharing the burden of rescue communally. Though firefighters do incur great burdens, they are also compensated for the risk. One could also imagine an institutional scheme whereby individuals who incur great costs to enact rescue-recall the man who must sacrifice his sports car to save a child on the railroad tracks-could be compensated for their personal loss. By spreading the demands of rescue among individuals, institutions can better coordinate rescues and collectively shoulder its burdens. The demands of individual rescue are less burdensome when addressed by institutions. ${ }^{23}$

Focusing on institutions provides a response to, and a diagnosis of, the demandingness concern. A primary reason why the demands of rescue can be so great is because poorly functioning or absent institutions cause rescue cases to proliferate. For example, wide inequalities in rates of childhood vaccinations within and between Indian states suggest that many children do not receive life-saving vaccinations because their state institutions are not just. ${ }^{24}$ If institutions were just and properly functioning, a great number of rescue cases would likely disappear.

In the absence of just institutions, the ethical challenge for individual potential rescuers remains. Recall the case of the Malian research subject with a cardiac defect. The cost to an individual researcher of airlifting her to a hospital for heart surgery would be very high. Assuming that the researcher is not wealthy, paying for the rescue himself might be praiseworthy, but not obligatory. Likewise, if the resources available to the research team are limited, it may not be obligatory for them to pay for the airlift. Moreover, if the opportunity costs to other needy patients is too large, a duty to rescue may be overridden.

But the story does not end there. Mali's lack of capacity to treat patients needing complex heart surgery is, plausibly, not an accident, but the result of systemic failures intranationally and internationally. If the researchers are not going to engage in costly rescues themselves, they can still work towards, and advocate for, improvements in Mali's healthcare system. Together with the efforts of others, and without any individual incurring excessive costs, it may be possible to expand the country's institutional capacity to respond to urgent needs. Recognising that an institutional response to predictable rescue needs may be appropriate can help concerned agents to focus on what should be changed without becoming paralysed or overwhelmed. We need not choose between doing nothing and sacrificing everything.

\section{Professional duties to rescue}

It is widely assumed that the individual duty to rescue just applies to moral agents as such. ${ }^{25}$ But, in fact, professionals frequently have additional (or more demanding) duties to rescue in virtue of their roles. ${ }^{26}$ For example, police and firefighters have a duty to rescue even at great risk to their own lives. Physicians must offer emergency medical assistance when not on the job. ${ }^{27}$ This explains and justifies the pull that urgent medical needs often have on healthcare professionals. The exact requirements of the professional duty to rescue will vary by profession: for example, firefighters may be required to risk their lives, though not their own personal resources, whereas doctors are rarely required to risk their lives, but may be required to devote their own time and resources. What these professions share, despite differences in the details, is a more demanding duty to rescue than the general, individual duty to rescue. 
The existence of these more stringent professional duties to rescue is uncontroversial: they are grounded in the profession's history, an implicit contract with society, and voluntary assumption of the role by the individual professionals. ${ }^{28}$ The professional context thereby explains the demanding force of the professional's duty to rescue. The professional context is also relevant to the duty's scope. For example, doctors have special obligations to their patients that justify partiality to these patients over others. More generally, professionals must take on greater costs to perform rescues within their area of expertise than outside it. Doctors have more demanding duties to rescue the sick and injured than people who are drowning. Lifeguards have an increased duty to rescue swimmers, though they don't have an increased duty to rescue people trapped in burning buildings; the latter is the professional domain of firefighters. All these agents have the same individual duties of easy rescue as other moral agents, but their responsibility increases when the rescue involves people who are the standard beneficiaries of their professional role.

In locating the scope of the professional duty to rescue, this conception provides a middle ground between two extremes: the rule of rescue unjustifiably advocates rescuing those with the most salient need, even at great opportunity cost. On the other side, consequentialism advocates always acting to bring about the optimific result. On the latter view, a heart surgeon should refuse to do a heart transplant when the resources for this costly surgery could save more lives if spent on, say, improving sanitation. A professional duty to rescue explains why the professional may and should favour rescuing a person to whom she is responsible at the opportunity cost of rescuing others (up to some threshold). Since the duty is generated from the professional role, it does not extend to rescues outside that role. ${ }^{\text {iv }}$

We noted earlier that individuals, particularly professionals, are often faced with rescue situations in which they are allocating institutional resources. Institutional duties to rescue and professional duties to rescue are therefore closely tied. An ideal society $^{\mathrm{v}}$ would assign responsibilities to rescue to individuals in conformity with the requirements of justice. However, this does not imply that individual professionals should always take an institutional view of the rescue cases they confront. Our institutions coordinate rescues, in part, by delegating them to professionals. But our professionals are not merely or even always institutional actors. The duties of a professional have a rich grounding in historical tradition, as well as social contract. Doctors will feel compelled to provide medical rescues to patients in their care regardless of whether this is the most efficient use of resources from the institutional standpoint. Indeed, this is at least partly desirable even from the institutional standpoint, for we wouldn't want our professionals on the ground worrying about allocation at each rescue. Firefighters shouldn't have to check a budget before responding to each call. That allocation decision happens at a societal or institutional level, not at the professional level.

Returning to the case of Oregon's Medicaid spending, the state might have been justified in refusing to pay for bone marrow transplants, on the grounds that providing alternative, more costeffective services would be more fair to the population it served;

\footnotetext{
${ }^{\text {iv }}$ Sheehan ${ }^{22}$ defends the rule of rescue as a product of agent-relative obligations. Such obligations arise most clearly in the context of role morality, such as the professional roles we focus on here.

${ }^{\mathrm{v}}$ An ideal society is one in which there is strict compliance with the principles of justice and reasonably favourable social conditions. ${ }^{30}$
}

however, the doctor of a patient like Coby Howard might still be justified in advocating for his treatment. In practice, the duties of professionals can come apart from those of institutions. The relationship between institutional and professional duties to rescue is a rich area for future study by bioethicists.

\section{CONCLUSIONS}

The duty of easy rescue and the morally endorsed rule of rescue lack the theoretical grounding to guide bioethicists in difficult cases. Though there is clearly an individual duty of easy rescue, it is not as unproblematic as bioethicists generally assume. Well-grounded limits on its force and scope are needed. The moralised rule of rescue might provide limits to an expansive duty to rescue, but we have argued that it is indefensible. Instead, bioethicists could make progress by focusing on institutional failings that allow rescue cases to proliferate, rendering some of them so costly. Focusing on an institutional duty to rescue can help individuals diagnose the source of the problem and provide an alternative avenue for people's urge to help by encouraging them to join with others to promote institutional change. Further, role-based duties of rescue can explain the greater pull of health-related rescue obligations for healthcare professionals. Doctors and others may have greater obligations to rescue the sick; but their roles also permit them to restrict the scope of their rescues.

Although thinking in terms of institutional and professional duties will improve bioethicists' employment of the duty to rescue, we have not solved all the problems that we have highlighted in this paper. The most difficult ethical dilemmas arise in non-ideal circumstances in which the potential rescuer faces substantial costs, but where her professional role does not provide clear guidance about incurring such costs. For cases like these, it is imperative that more conceptual work be done to elucidate the foundation, scope and force of the individual duty to rescue. Additionally, calling attention to professional morality to better understand the duty to rescue is only helpful when we have developed accounts of the profession in question. For example, the role morality of the medical researcher remains a contested area in need of further scholarship. ${ }^{31} 32$

Accordingly, we propose four research priorities for the ethics of rescue: (1) develop a foundational justification for individual duties to rescue that can specify their scope and force; (2) investigate how institutional solutions to desperate need can solve practical concerns about the burdensome demands of rescue; (3) analyse and develop accounts of the duty to rescue by professional role, focusing, in particular, on clinicians and researchers; and, finally, (4) determine how the different rescue duties should be balanced against each other and against other duties of individuals, professionals and institutions. Meeting each of these aims would advance our understanding of how clinicians, researchers and policy makers should respond to people in desperate medical need.

Contributors TR was responsible for the conception and design of the paper; drafting the article and revising it for important intellectual content, and final approval of the version to be published. JM was responsible for the conception and design of the paper, revising it for important intellectual content, and final approval of the version to be published. Both authors are guarantors of the paper.

Funding This work was supported, in part, by intramural funds from the National Institutes of Health Clinical Center.

Disclaimer The views expressed are the authors' own. They do not represent the position or policy of the National Institutes of Health, US Public Health Service, or the Department of Health and Human Services.

Competing interests None.

Provenance and peer review Not commissioned; externally peer reviewed. 


\section{REFERENCES}

1 Hawkins J. Justice and placebo controls. Soc Theory Pract 2006;32(3):467-96.

2 Miller FG, Mello MM, Joffe S. Incidental findings in human subjects research: what do investigators owe research participants? J Law Med Ethics 2008;36(2):271-79.

3 Merritt MW, Taylor HA, Murray LC. Ancillary care in community-based public health intervention research. Am J Public Health 2010;100(2):211-16.

4 Harris J. Scientific research is a moral duty. J Med Ethics 2005;31:242-48.

5 Howard RJ. We have an obligation to provide organs for transplantation after we die. Am J Transplant 2006;6:1786-89.

6 Largent EA, Pearson SD. Which orphans will find a home? Hastings Cent Rep 2012;42(1):27-34.

7 Jonsen A. Bentham in a box: technology assessment and health care allocation. Law Med Health Care 1986;14(3-4):172-74.

8 McKie J, Richardson J. The rule of rescue. Soc Sci Med 2003;56(12):2407-19.

9 Honeybul S, Gillett GR, Ho KM, et al. Neurotrama and the rule of rescue. J Med Ethics 2011;37:707-10.

10 Singer P. Famine, affluence and morality. Philos Public Aff 1972;1:229-43.

11 Beauchamp TL, Childress JF. Principles of biomedical ethics. New York: Oxford University Press, 2009:202.

12 Unger P. Living high and letting die: our illusion of innocence. New York: Oxford University Press, 1996:135-36.

13 Bennett-Smith M. Darrell Krushelnicki, 'Hummer Hero,' uses vehicle to shield four children from oncoming car. Huffington Post 2012. http://www.huffingtonpost.com/ 2012/09/06/hummer-hero-darrell-krushelnicki-saves-four-children_n_1861866.html (accessed 10 Jun 2013).

14 Tarasoff $v$ the Regents of the University of California, 551 P2d 334 (Cal 1976).

15 Shephard $v$ Redford Community Hospital, 151 Mich. App. 242, appeal denied, 431 Mich. 872(1988); Pate v Threlkel, 661 So2d. 278 (Fla 1995); Safer v Pack, 677 A2d 1188, cert. den'd, 683 A2d 1163 (NJ 1996).

16 Offit $\mathrm{K}$, Groeger $\mathrm{E}$, Turner $\mathrm{S}$, et al. The 'duty to warn' a patient's family members about hereditary disease risks. JAMA 2004;292(12):1472.
17 Dickert N, Wendler D. Ancillary care obligations of medical researchers. JAMA 2009:302(4):424-28.

18 Belsky L, Richardson HS. Medical researchers' ancillary clinical care responsibilities. BMJ 2004;328:1494-6.

19 Cullity G. The moral demands of affluence. New York: Oxford University Press, 2004.

20 Murphy LB. Moral demands in nonideal theory. New York: Oxford University Press, 2003:127-33.

21 Hadorn DC. Setting health care priorities in oregon: cost-effectiveness meets the rule of rescue. JAMA 1991;265(17):2218-25.

22 Sheehan M. Resources and the rule of rescue. J Appl Philos 2007;24(4):354-66.

23 Feinberg J. The moral limits of the criminal law: harm to others. New York: Oxford University Press, 1984:165-71.

24 Mathew JL. Inequity in childhood immunization in India: a systematic review. Indian Pediatr 2012;49(3):203-23.

25 Richardson HS, Belsky L. The ancillary-care responsibilities of medical researchers: an ethical framework for thinking about the clinical care that researchers owe their subjects. Hastings Cent Rep 2004;34(1):25-33.

26 Rulli T, Emanuel EJ, Wendler D. The moral duty to buy health insurance. JAMA 2012;308(2):137-38.

27 Code of Medical Ethics. American Medical Association. http://www.ama-assn.org/ ama/pub/physician-resources/medical-ethics/code-medical-ethics/principles-medicalethics.page (accessed 17 Dec 2012).

28 Arras J. The fragile web of responsibility: AIDS and the duty to treat. Hastings Cent Rep 1988;18(2):10-20.

29 Daniels N. Duty to treat or right to refuse? Hastings Cent Rep 1991;21(2):36-46.

30 Rawls J. A theory of justice. Cambridge, MA: Belnkap Press Harvard University, 1971:351.

31 Freedman B. Equipoise and the ethics of clinical research. N Engl J Med 1987; 317(3):141-5.

32 Miller FG, Brody H. A critique of clinical equipoise: therapeutic misconception in the ethics of clinical trials. Hastings Cent Rep 2003;33(3):19-28. 